\title{
Epidemiological Characteristics of Traffic and Non-traffic Injuries and Quality of Emergency Medical Services in Southern Thailand
}

\author{
Patcharee Prommoon, M.N.S. ${ }^{1}$, Thanom Phibalsak, M.N.S. ${ }^{1}$, Janya Netwachirakul, B.N.S. \\ Mayuree Mekthat, M.Sc. ${ }^{1}$, Walailuk Jitpiboon, M.Sc. ${ }^{2}$, Rassamee Sangthong, M.D., Ph.D. ${ }^{2,3}$ \\ ${ }^{1}$ Emergency Department, Hatyai Hospital, Hat Yai, Songkhla 90110, Thailand. \\ ${ }^{2}$ Epidemiology Unit, Prince of Songkla University, Hat Yai, Songkhla 90110, Thailand. \\ ${ }^{3}$ Research Unit for Kids and Youth Development, Prince of Songkla University, Hat Yai, Songkhla 90110, Thailand. \\ Received 26 March 2020 • Revised 31 July 2020 • Accepted 13 August 2020 • Published online 1 February 2021
}

\begin{abstract}
:
Objective: This study aimed to report the situation of injuries and emergency medical services in southern Thailand.

Material and Methods: Data from the Injury Surveillance system of a Level 1 Trauma Center Hospital in lower southern Thailand during 2012-2016 were extracted. Trends in epidemiological characteristics of both traffic and non-traffic injuries and emergency medical services were described. Logistic regression was used for the analysis.
\end{abstract}

Results: The number of patients admitted to emergency departments due to traffic and non-traffic injuries was stable over the five-year period $(n=102,840)$. Traffic injuries involving motorcycles and falls were the two leading causes of injury. Most were adults aged 19-60 years (62.5\%). The most common risky behaviors were driving a motor vehicle without wearing a seatbelt (81.9\%) and riding a motorcycle without wearing a helmet (71.7\%). Alcohol and drug use were relatively low but significantly increased the odds of sustaining a severe/critical injury. Significant predictors of severe/ critical non-traffic injury included drowning [odds ratio $(\mathrm{OR})=29.7,95 \%$ confidence interval $(\mathrm{Cl})=11.9-74.7$ ], self-harm/ suicide $(\mathrm{OR}=12.6,95 \% \mathrm{Cl}=9.2-17.3)$, and bites/stings from poisonous animals $(\mathrm{OR}=8.1,95 \% \mathrm{Cl}=6.1-10.8)$. The use of Emergency Medical Services (EMS) was low but increased over time. The main challenge was delivering appropriate EMS for different levels of injury. The percentage of health care staff who performed advanced life support appropriately for critically injured patients ranged from $95.5 \%$ to $100.0 \%$ while for severely injured patients, ranged from $93.9 \%$ to $100.0 \%$.

Contact: Rassamee Sangthong, M.D., Ph.D.

Epidemiology Unit, Prince of Songkla University, Hat Yai, Songkhla 90110, Thailand.

Research Unit for Kids and Youth Development, Prince of Songkla University,

Hat Yai, Songkhla 90110, Thailand.

E-mail: rassamee.s@psu.ac.th

(c) 2021 JHSMR. Hosting by Prince of Songkla University. All rights reserved.

This is an open access article under the CC BY-NC-ND license

(http://www.jhsmr.org/index.php/jhsmr/about/editorialPolicies\#openAccessPolicy).
J Health Sci Med Res 2021;39(4):273-282 doi: $10.31584 /$ jhsmr.2021783 www.jhsmr.org 
Conclusion: Traffic and non-traffic injuries were high and the use of EMS was still low in southern Thailand.

Keywords: emergency medical service, injury surveillance system, non-traffic, traffic

\section{Introduction}

Premature deaths among people aged 15-29 years are mainly caused by road traffic injuries while other injuries, such as suicide and drowning, are among the top ten globally. ${ }^{1}$ Road fatality rates in Thailand were estimated to be as high as 36.2 per 100,000 population in 2013 , the second highest rate in the world. ${ }^{2,3}$ The Thai government, led by the Bureau of Non-Communicable Diseases, aims to reduce the traffic fatality rate to below 10 per 100,000 population in $2020 .{ }^{4}$ The rate of deliberate self-harm and suicide in Thailand increased from 7.9 in 2003 to 12.9 per 100,000 population in 2016..$^{1,5,6}$ Similarly, drowning has become the leading cause of death among people aged $<15$ years. ${ }^{4}$ In South Korea, suicide ranks number one as the cause of death amongst adolescents. In Eastern Ethiopia, it is injuries due to conflict and road traffic accidents. ${ }^{7,8}$ Effective interventions and policies to prevent injuries and good pre-hospital services are urgently needed.

Thailand's Injury Surveillance database was developed by the Bureau of Epidemiology, Department of Disease Control, Ministry of Public Health in $1993^{9}$ with the aim to monitor the situation and improve prevention pre-hospital care at the local and national levels. The Injury Surveillance database can be used to assess and monitor injuries and the quality of pre-hospital services. As part of a level 1 Trauma Center in southern Thailand, we examined the epidemiological characteristics of traffic and non-traffic injuries and the quality of the pre-hospital care to understand the current situation.

\section{Material and Methods}

A retrospective cohort study was conducted using data from the Injury Surveillance database of a Level 1 Trauma Center Hospital, Ministry of Public Health in the lower southern region of Thailand. The database contains a total of 133 variables including transport method to the hospital, pre-hospital care, demographic data, type(s) of injury, risk behaviors, vital clinical data on arrival, and diagnosis on discharge. ${ }^{9}$ Injuries sustained between 2012 and 2016 were included in this study.

Transport to hospital was recorded as by oneself, others, or via the emergency medical service (EMS). The EMS was classified into three levels ${ }^{10}$ based on the competence of health personnel and facilities available in the vehicle. For the "Advanced Life Support" level, the healthcare worker must be a doctor or nurse who has completed appropriate training and be qualified to maintain airway, control bleeding, give fluid replacement and/or medical injections, stabilize fractures, immobilize the cervical spine and transfer a critical patient safely. Health workers at the "Basic Life Support" level must have completed 110 hours of training, be able to stop bleeding, give appropriate oral medications, transfer a patient safely and assist in childbirth. A "First Responder" is anyone who has completed 40 hours of first aid training and knows how to transfer a patient safely.

Injury and external causes of injury were defined by the International Classification of Diseases, $10^{\text {th }}$ edition (ICD-10) chapters 19 and 20, respectively. ${ }^{11,12}$ Injuries were defined broadly into traffic and non-traffic types. Risk behaviors at the time of sustaining the injury included alcohol and substance use, not wearing a seatbelt while driving (or travelling in) a vehicle, not wearing a helmet while riding a motorcycle, and mobile phone use. Severity of injury was measured by the Emergency Severity Index (ESI) Version 4 which categorizes from very mild (1) to critical (5). ${ }^{13}$ Only the last two years (2015-2016) of data on ESI were available for analysis. 
The data were recorded by a well-trained triage nurse from all injured patients who visited the emergency unit. A hospital data analyst then coded and entered the data into a Microsoft Access database.

\section{Ethical considerations}

This study obtained approval from the Ethics Board Committee, Faculty of Medicine, Prince of Songkla University (No. 60-341-19-9).

\section{Statistical analysis}

The $\mathrm{R}$ program was used for all statistical analysis. ${ }^{14}$ Descriptive statistics were used to examine the epidemiological nature of the individual characteristics, magnitudes and types of injuries, time of injury, and trends over the five-year period including during the special New Year and Songkran festival holidays. Use of EMS was also examined and its quality assessed based on severity of the patient's injuries and appropriateness of services delivered. Severe injuries were defined as ESI $\geq 3$ and factors associated with severe injury were analyzed using multivariate logistic regression separately for motorcycle and motor vehicle accidents and for non-traffic injuries. Two-sided $p$-values were used and significance was set at $<0.05$.

Insufficient pre-hospital care was defined for patients who were severely or critically injured and did not receive appropriate service, such as airway maintenance, bleeding control, immobilization of cervical spine, splint/slap use or fluid replacement. Excessive pre-hospital care was defined for patients who were mildly or moderately injured and received any of the above-mentioned services unnecessarily.

\section{Results}

\section{Epidemiological characteristics of the injuries Victims}

A total of 102,840 patients were admitted to emergency departments as a result of injuries received during 1 January 2012-31 December 2016. Table 1 shows the baseline characteristics of the study patients. Males outnumbered females by a ratio of $1.6: 1$. Most patients were aged 19-60 years while about one-third were children or adolescents. The highest work category was laborers (31.5\%), followed by unemployed (22.5\%) and students (19.1\%). The most common risk behavior was not wearing a seatbelt among motor vehicle drivers (81.9\%) followed by not wearing a helmet among motorcyclists $(71.7 \%)$. Driving under the influence of alcohol (9.8\%) and/or other drugs $(0.4 \%)$ was less common.

Table 1 Characteristics of injured patients admitted to a Level 1 Trauma Center Hospital in southern Thailand, 2012-2016 ( $n=102,840)$

\begin{tabular}{|c|c|c|}
\hline Characteristic & Number & $\%$ \\
\hline \multicolumn{3}{|l|}{ Gender } \\
\hline Male & 63,151 & 61.4 \\
\hline Female & 39,689 & 38.6 \\
\hline \multicolumn{3}{|l|}{ Age group (years) } \\
\hline $0-6$ & 9,632 & 9.4 \\
\hline $7-18$ & 20,361 & 19.8 \\
\hline $19-60$ & 64,299 & 62.5 \\
\hline$>60$ & 8,548 & 8.3 \\
\hline \multicolumn{3}{|l|}{ Occupation } \\
\hline None (children <5 years old) & 8,279 & 8.1 \\
\hline Student & 19,690 & 19.1 \\
\hline Unemployed & 23,144 & 22.5 \\
\hline Laborer & 32,373 & 31.5 \\
\hline Government officer & 7,140 & 6.9 \\
\hline Businessperson & 3,595 & 3.5 \\
\hline Farmer & 4,047 & 3.9 \\
\hline Others & 4,572 & 4.5 \\
\hline \multicolumn{3}{|l|}{ Risky behaviors } \\
\hline Not wearing seatbelt ${ }^{\dagger}(n=2,957)$ & 2,421 & 81.9 \\
\hline Not wearing helmet ${ }^{\ddagger}(n=34,132)$ & 24,478 & 71.7 \\
\hline Alcohol use $(n=100,192)$ & 9,776 & 9.8 \\
\hline Other drugs use $(n=100,257)$ & 399 & 0.4 \\
\hline Mobile phone use $(n=100,853)$ & 30 & $<0.1$ \\
\hline
\end{tabular}

${ }^{\dagger}$ Among motor vehicle drivers. ${ }^{\ddagger}$ Among motorcycle riders. 
Magnitude, trend, types of injuries and use of emergency medical services

As shown in Table 2, the numbers of admissions due to injuries were consistent across the five-year period. Non-traffic injuries were more common than traffic injuries. Injuries involving motorcycles were the most common traffic injury followed by injuries involving private vehicles such as pick-up trucks, cars, and bicycles. Injuries involving public transport vehicles such as buses and taxis were rare. The most common causes of non-traffic injuries were collisions, falls, body assaults, and animal bites. Self-harm and suicide, poisoning, and drowning were uncommon.
The overall utilization of the emergency medical services was $24.2 \%$ and the rate increased each year. Use of the service among patients with traffic injuries was substantially higher than that of patients with non-traffic injuries.

\section{Time of injury}

As shown in Figure 1, the distributions of the time of injury for both traffic and non-traffic injuries were bimodal, with peaks occurring between 06:00-8:00 and between 17:00-18:00 for traffic injuries and between 12:00-13:00 and between 17:00-18:00 for non-traffic injuries.

Table 2 Types of injuries and use of emergency medical services by year, 2012-2016

\begin{tabular}{|c|c|c|c|c|c|}
\hline Type of injury & 2012 & 2013 & 2014 & 2015 & 2016 \\
\hline All injuries & $20,090(19.5)$ & $20,045(19.5)$ & $20,526(20.0)$ & $21,436(20.8)$ & $20,743(20.2)$ \\
\hline Traffic (type of vehicle) & $n=8,662$ & $n=8,262$ & $\mathrm{n}=8,172$ & $\mathrm{n}=8,571$ & $\mathrm{n}=8,315$ \\
\hline Motorcycle & 7,211 (83.2) & 6,996 (84.7) & 6,929 (84.8) & $7,208(84.1)$ & $7,023(84.5)$ \\
\hline Pick-up truck & $379(4.4)$ & $372(4.5)$ & 321 (3.9) & $371(4.3)$ & $374(4.5)$ \\
\hline Bicycle/tricycle & 290 (3.3) & $266(3.2)$ & $291(3.6)$ & $391(4.6)$ & $303(3.6)$ \\
\hline Private car & $189(2.2)$ & $156(1.9)$ & $188(2.3)$ & 159 (1.9) & $211(2.5)$ \\
\hline Truck/caravan & $52(0.6)$ & $45(0.5)$ & $38(0.5)$ & $41(0.5)$ & $34(0.4)$ \\
\hline Minibus/bus/taxi & $35(0.4)$ & $34(0.4)$ & $30(0.4)$ & $24(0.3)$ & $43(0.5)$ \\
\hline Van & $45(0.5)$ & $21(0.3)$ & $37(0.5)$ & $36(0.4)$ & $26(0.3)$ \\
\hline Others & $461(5.3)$ & $372(4.5)$ & $338(4.1)$ & $341(4.0)$ & $301(3.6)$ \\
\hline EMS use & 2,853 (32.9) & $2,864(34.7)$ & 2,975 (36.4) & $3,481(40.6)$ & $3,466(41.7)$ \\
\hline Non-traffic & $n=11,428$ & $n=11,783$ & $n=12,354$ & $n=12,865$ & $n=12,428$ \\
\hline Collision & 4,460 (39.0) & $4,548(38.6)$ & 4,432 (35.9) & 4,535 (35.3) & 4,335 (34.9) \\
\hline Fall & $3,174(27.8)$ & $3,269(27.7)$ & $3,639(29.5)$ & 3,761 (29.2) & 3,934 (31.7) \\
\hline Physical assault & 1,525 (13.3) & 1,526 (13.0) & 1,635 (13.2) & $1,700(13.2)$ & $1,492(12.0)$ \\
\hline Animal attack & 839 (7.3) & $1102(9.4)$ & $1,312(10.6)$ & $1,451(11.3)$ & 1,377 (11.1) \\
\hline Self-harm & $334(2.9)$ & $298(2.5)$ & $270(2.2)$ & $263(2.0)$ & $236(1.9)$ \\
\hline Poisoning & $318(2.8)$ & $289(2.5)$ & $326(2.6)$ & $329(2.6)$ & $290(2.3)$ \\
\hline Drowning & $22(0.2)$ & $15(0.1)$ & $22(0.2)$ & $16(0.1)$ & $18(0.1)$ \\
\hline Others & $756(6.6)$ & $736(6.2)$ & $718(5.8)$ & $810(6.3)$ & $746(6.0)$ \\
\hline EMS use & $918(8.0)$ & $938(8.0)$ & $941(7.6)$ & $1,173(9.1)$ & 1,272 (10.2) \\
\hline
\end{tabular}

Numbers in the table are frequency (\%)

EMS=emergency medical services 

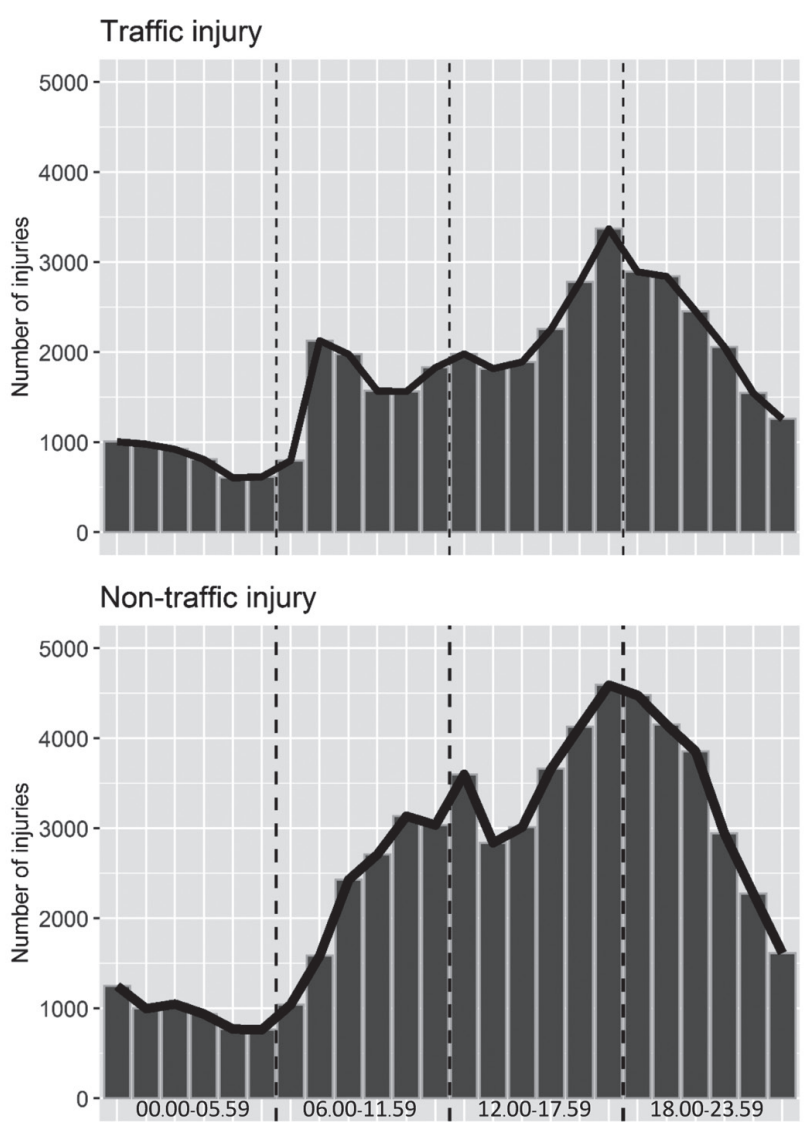

Figure 1 Distribution of time of injury by injury type

\section{Critical period of injuries during the New Year} and Thai Traditional New Year holidays

Figure 2 shows the number of injuries occurring per day during the international and Thai traditional (Songkran) New Year holiday festivals, periods of relatively higher injuries compared to other times of the year. During the international New Year period, the highest numbers of admissions due to traffic and non-traffic injuries occurred on New Year's Eve and New Year's day, respectively. During the Songkran festival, the highest number of admissions due to injuries occurred on April 13, Songkran day.

\section{Associated factors of severe injury}

Table 3 shows the factors associated with severe injury for persons injured from motorcycle accidents, motor vehicle accidents, and non-traffic injuries. Among those involved in motorcycle accidents, males [odds ratio $(\mathrm{OR})=1.6,95 \%$ confidence interval $(\mathrm{Cl})=1.3-1.9]$ and those aged more than 60 years $(\mathrm{OR}=2.3,95 \% \mathrm{Cl}$ : 1.5-3.5) were more likely to have severe injuries as were those who did not wear a helmet $(\mathrm{OR}=2.8)$, used alcohol $(\mathrm{OR}=3.1)$ or other drugs $(\mathrm{OR}=4.9)$, and did not use the EMS (OR=2.7). The only significant risk factor for severe injury among those involved in motor vehicle accidents was not wearing a seatbelt $(\mathrm{OR}=2.2,95 \% \mathrm{Cl}: 1.0-4.8)$. For non-traffic injuries, males were more likely to have a severe injury $(\mathrm{OR}=2.3,95 \% \mathrm{Cl}: 2.0-2.6)$ as were those aged $>60$ years $(\mathrm{OR}=2.0)$, and those who used alcohol $(\mathrm{OR}=1.6)$ or other drugs $(\mathrm{OR}=3.0)$. Non-use of the EMS was associated with not having severe injuries (OR=0.7, 95\% Cl: $0.6-$ 0.8). Compared to injuries caused by animals, drowning $(\mathrm{OR}=29.7)$, self-harm $(\mathrm{OR}=12.6)$, and poisoning $(\mathrm{OR}=8.1)$ were significantly more likely to cause severe injuries.

\section{Coverage and quality of pre-hospital care by}

\section{EMS}

Overall, $24.2 \%$ of patients received pre-hospital care by EMS. Among these, Basic Life Support (57.1\%) was the most common service followed by First Responder (38.3\%) and Advanced Life Support (4.6\%). Table 4 shows the appropriateness of EMS by severity of injury. Less than half of all patients received appropriate EMS services with one-third receiving an insufficient level of care and one-fifth receiving an excessive level of care. Additional analysis revealed that the fatality rate was highest $(78.6 \%)$ among patients who received insufficient pre-hospital care compared to $21.4 \%$ among those who received appropriate 
care. Among those who were critically or severely injured, $92.9 \%$ received an insufficient level of care while $63.4 \%$

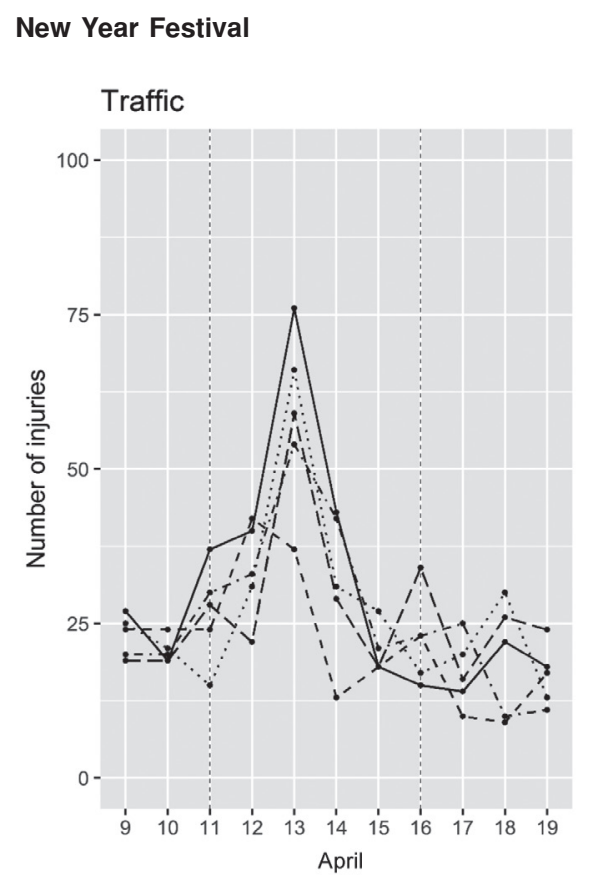

Songkran Festival

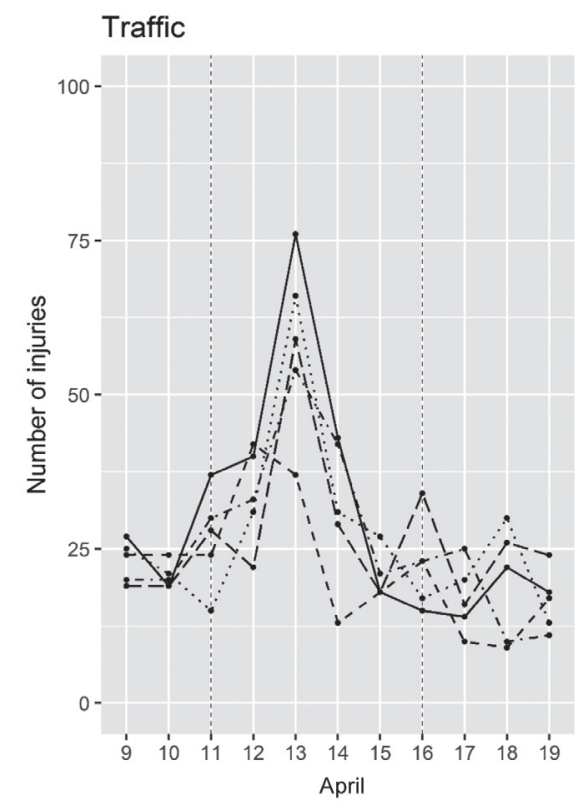

of those whose injury was mild or very mild received an excessive level of care.
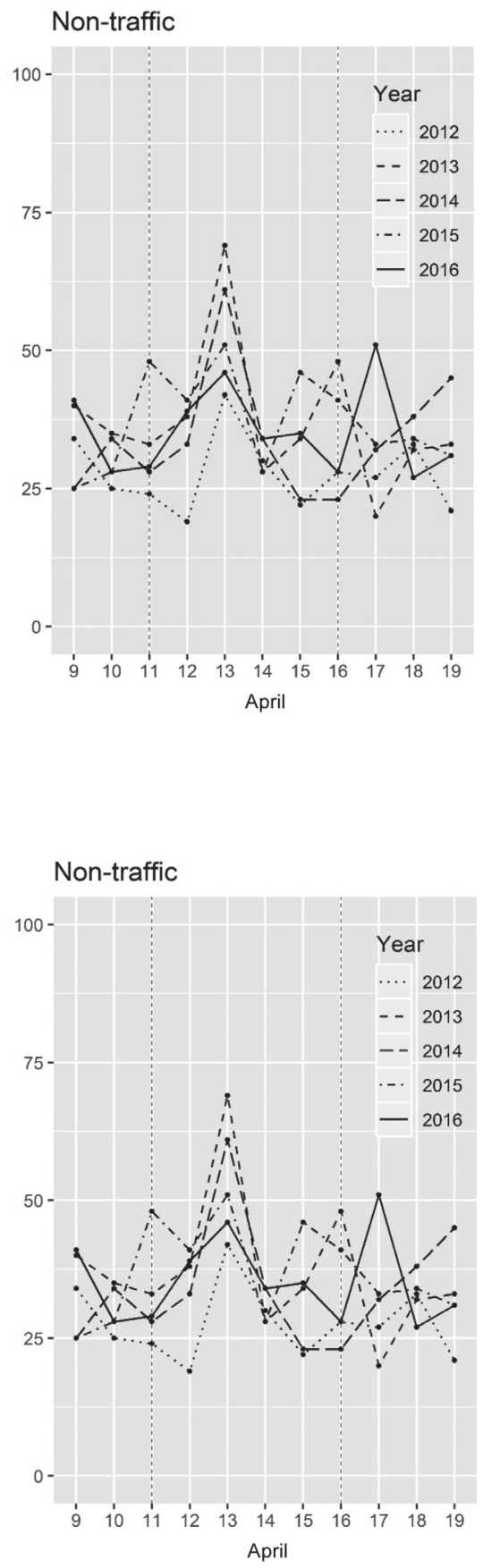

Figure 2 Number of injuries per day during the New Year's and Songkran festivals, 2012-2016 
Table 3 Associated factors for severe/critical injury by type of injury

\begin{tabular}{|c|c|c|c|}
\hline Factor & $\begin{array}{l}\text { Crude OR } \\
(95 \% \mathrm{Cl})\end{array}$ & $\begin{array}{l}\text { Adjusted OR } \\
(95 \% \mathrm{Cl})\end{array}$ & $p$-value \\
\hline \multicolumn{4}{|l|}{ Motorcycle accidents $(n=12,738)$} \\
\hline Gender (Ref.=Female) & & & $<0.001$ \\
\hline Male & $2.1(1.8,2.4)$ & $1.6(1.3,1.9)$ & \\
\hline Age (years) (Ref.=0-6) & & & $<0.001$ \\
\hline $7-18$ & $0.7(0.5,1.0)$ & $0.8(0.6,1.2)$ & \\
\hline $19-60$ & $0.9(0.6,1.3)$ & $1.0(0.7,1.4)$ & \\
\hline$>60$ & $2.1(1.4,3.1)$ & $2.3(1.5,3.5)$ & \\
\hline Time of injury (hr) (Ref.=06:00-11:59) & & & $<0.001$ \\
\hline $00: 00-05: 59$ & $1.1(0.9,1.4)$ & $0.5(0.4,0.7)$ & \\
\hline $12: 00-17: 59$ & $1.1(0.9,1.3)$ & $1.1(0.9,1.3)$ & \\
\hline $18: 00-23: 59$ & $1.2(1.0,1.4)$ & $0.8(0.6,1.0)$ & \\
\hline Not wearing helmet & $2.9(2.4,3.5)$ & $2.8(2.3,3.4)$ & $<0.001$ \\
\hline Alcohol use & $3.2(2.7,3.7)$ & $3.1(2.6,3.7)$ & $<0.001$ \\
\hline Drug use & $5.9(2.7,13.1)$ & $4.9(2.1,11.6)$ & $<0.001$ \\
\hline No EMS use & $2.6(2.3,3.1)$ & $2.7(2.3,3.2)$ & \\
\hline \multicolumn{4}{|l|}{ Automobile accidents $(\mathrm{n}=307)$} \\
\hline Gender (Ref.=Female) & & & 0.987 \\
\hline Male & $1.0(0.5,1.8)$ & $1.0(0.5,1.9)$ & \\
\hline Age (years) (Ref.=0-6) & & & 0.739 \\
\hline $7-18$ & $1.1(0.2,7.2)$ & $1.3(0.2,8.2)$ & \\
\hline $19-60$ & $1.3(0.3,6.0)$ & $1.6(0.3,8.0)$ & \\
\hline$>60$ & $0.7(0.1,5.7)$ & $0.8(0.1,7.0)$ & \\
\hline Time of injury (hr) (Ref.=06:00-11:59) & & & 0.291 \\
\hline $00: 00-05: 59$ & $0.6(0.2,1.4)$ & $0.4(0.1,1.1)$ & \\
\hline $12: 00-17: 59$ & $0.8(0.3,1.8)$ & $0.8(0.3,1.9)$ & \\
\hline $18: 00-23: 59$ & $1.0(0.4,2.3)$ & $0.9(0.4,2.2)$ & \\
\hline Not wearing seatbelt & $1.8(0.9,3.8)$ & $2.2(1.0,4.8)$ & 0.032 \\
\hline Alcohol use & $0.9(0.5,1.9)$ & $1.5(0.6,3.8)$ & 0.381 \\
\hline No EMS use & $1.7(0.9,3.2)$ & $1.9(1.0,3.6)$ & 0.060 \\
\hline \multicolumn{4}{|l|}{ Non-traffic injuries $(n=23,737)$} \\
\hline Gender (Ref.=Female) & & & $<0.001$ \\
\hline Male & $1.7(1.5,1.9)$ & $2.3(2.0,2.6)$ & \\
\hline Age (years) (Ref.=0-6) & & & $<0.001$ \\
\hline $7-18$ & $1.3(1.1,1.7)$ & $1.0(0.8,1.3)$ & \\
\hline $19-60$ & $1.9(1.5,2.3)$ & $1.2(1.0,1.5)$ & \\
\hline$>60$ & $2.1(1.6,2.6)$ & $2.0(1.6,2.6)$ & \\
\hline Time of injury (hr) (Ref.=06:00-11:59) & & & 0.002 \\
\hline $00: 00-05: 59$ & $1.6(1.3,1.9)$ & $0.9(0.7,1.1)$ & \\
\hline $12: 00-17: 59$ & $1.1(0.9,1.2)$ & $1.1(0.9,1.3)$ & \\
\hline 18:00-23:59 & $1.0(0.9,1.2)$ & $0.8(0.7,1.0)$ & \\
\hline Type of injury (Ref.=Animal attack) & & & $<0.001$ \\
\hline Accident & $0.5(0.4,0.7)$ & $0.4(0.3,0.5)$ & \\
\hline Fall & $1.3(1.1,1.7)$ & $1.1(0.9,1.4)$ & \\
\hline Assault & $3.4(2.7,4.3)$ & $2.8(2.2,3.5)$ & \\
\hline Self-harm & $17.0(12.8,22.6)$ & $12.6(9.2,17.3)$ & \\
\hline Poisoning ${ }^{\dagger}$ & $8.7(6.6,11.5)$ & $8.1(6.1,10.8)$ & \\
\hline Drowning & $29.8(12.4,71.9)$ & $29.7(11.9,74.7)$ & \\
\hline Others & $2.2(1.7,3.0)$ & $1.8(1.3,2.3)$ & \\
\hline Alcohol use & $3.2(2.7,3.8)$ & $1.6(1.3,2.0)$ & $<0.001$ \\
\hline Drug use & $14.9(10.6,20.8)$ & $3.0(2.0,4.6)$ & $<0.001$ \\
\hline No EMS use & $0.4(0.4,0.5)$ & $0.7(0.6,0.8)$ & $<0.001$ \\
\hline
\end{tabular}

OR=odds ratio, $\mathrm{Cl}=$ confidence interval, EMS=emergency medical services, Ref=reference group

${ }^{\dagger}$ Includes snake bites and eating poisonous plants. 
Table 4 Appropriateness of emergency medical services by severity of injury

\begin{tabular}{|c|c|c|c|c|}
\hline \multirow{2}{*}{ Severity of injury } & \multirow{2}{*}{ Number } & \multicolumn{3}{|c|}{ Appropriateness of services, $n(\%)$} \\
\hline & & Insufficient & Appropriate & Excessive \\
\hline All & 9,029 & $2,862(31.7)$ & $4,101(45.4)$ & 2,066 (22.9) \\
\hline Severe to critical & 772 & $717(92.9)$ & $55(7.1)$ & - \\
\hline Moderate & 5,253 & $2,145(40.8)$ & $2,947(56.1)$ & 161 (3.1) \\
\hline Mild to very mild & 3,004 & - & $1,099(36.6)$ & $1,905(63.4)$ \\
\hline
\end{tabular}

Not applicable

Table 5 Percentage of services appropriately delivered to patients with critical and severe injuries by emergency medical services level $(n=772)$

\begin{tabular}{|c|c|c|c|c|c|c|}
\hline \multirow{2}{*}{ EMS level } & \multirow{2}{*}{ Number } & \multicolumn{5}{|c|}{ Appropriate service, $n(\%)$} \\
\hline & & $\begin{array}{l}\text { Airway } \\
\text { maintenance }\end{array}$ & $\begin{array}{l}\text { Bleeding } \\
\text { control }\end{array}$ & $\begin{array}{l}\text { Immobilization } \\
\text { of cervical-spine }\end{array}$ & Splint/slab & $\begin{array}{l}\text { Fluid } \\
\text { replacement }^{\dagger}\end{array}$ \\
\hline \multicolumn{7}{|l|}{ Critical injury } \\
\hline Advanced life support & 22 & $22(100.0)$ & $22(100.0)$ & $22(100.0)$ & $22(100.0)$ & $21(95.5)$ \\
\hline Basic life support & 104 & $78(75.0)$ & $96(92.3)$ & $93(89.4)$ & $92(88.5)$ & - \\
\hline First responder & 77 & $55(71.4)$ & $71(92.2)$ & $68(88.3)$ & $70(90.9)$ & - \\
\hline \multicolumn{7}{|l|}{ Severe injury } \\
\hline Advanced life support & 33 & $33(100.0)$ & $31(93.9)$ & $32(97.0)$ & $31(93.9)$ & $32(97.0)$ \\
\hline Basic life support & 295 & 227 (93.9) & $283(95.9)$ & $276(93.6)$ & $289(98.0)$ & - \\
\hline First responder & 241 & $217(90.0)$ & $229(95.0)$ & $225(93.4)$ & $238(98.8)$ & - \\
\hline
\end{tabular}

${ }^{\dagger}$ Assessment of fluid replacement was omitted for basic life support and first responder levels.

EMS=emergency medical services

Table 5 shows the quality of services delivered to patients with severe and critical injuries by EMS level. The appropriate service for those requiring advanced life support was given to all critically injured patients except for fluid replacement $(95.5 \%)$ but between $93.9 \%$ and $100.0 \%$ of severely injured patients. For critically injured patients requiring basic life support, the quality of services delivered ranged from $75.0 \%$ to $92.3 \%$ and for severely injured patients the rate ranged from $93.9 \%$ to $98.0 \%$.

\section{Discussion}

The study revealed dual problems of traffic and non-traffic injuries representing the burden of disability and death in youth and adults in the study areas. Motorcycle injuries and falls were the leading causes of injury requiring hospital care. Although drowning self-harm, and poisoning were comparatively less common, these types of injuries significantly increased the likelihood of a severe/critical injury.

For traffic injuries, $63.9 \%$ were contributed by road users. ${ }^{15}$ In 1979 Thailand legislated the Road Traffic Act. B.E. $2522^{15}$ requiring motorcycle helmets and front-seat seatbelts to reduce the severity of traffic injuries. However, this study found a high rate of injuries in which motor vehicle drivers or passengers were not wearing their seatbelts $(81.9 \%)$ or motorcycle riders who were not wearing a helmet (71.7\%). A national report in (2018) found that $79.9 \%$ of motorcycle riders did not wear a helmet, with the highest 
percentages of non-use among 15-19 years old and young adults. ${ }^{4}$ The poor compliance to this road safety practice has led to traffic fatality rates of $19.2 \%$ and $12.9 \%$ among populations aged 15-19 and 20-24 years, respectively. ${ }^{4}$ Public awareness, public education, and law enforcement should thus be further improved.

Alcohol and drug use among accident victims were relatively low in this study but should not be neglected. The low numbers reported may be due to declining trends of regular drinkers and increasing numbers of Muslims residing in this region. ${ }^{16,17}$ Drunk driving and driving under the influence of a controlled substance contributed to $6.9 \%$ and $<0.1 \%$ of all road traffic accidents, respectively. ${ }^{15}$ Our study found that alcohol and drug use substantially increased the likelihood of severe injury, especially among victims of motorcycle accidents and other non-traffic injuries, a result consistent with national reports. ${ }^{4}$

The peak time of injury was during the late afternoon and evening, a result consistent with reports at the regional and national levels. ${ }^{4}$ This finding could suggest more human resources should be allocated during these high-risk periods. In Thailand, road safety interventions are increased during the New Year's and Songkran holiday periods. Our study reported a high or even higher incidence of non-traffic injuries during those two periods which calls for interventions to be increased or enhanced.

The utilization of pre-hospital care increased over time and the rate was higher for traffic injuries compared to non-traffic injuries. However, the EMS utilization rate $(24.2 \%)$ was still substantially lower than the minimum expected rate of $60.0 \%{ }^{18}$ EMS often encounter challenges in delivering the appropriate level of service to reach a high quality of pre-hospital care. A study from Iraq reported that good pre-hospital care could reduce mortality rates by $13.0 \%{ }^{19}$ Thus, training of EMS personnel and assessment for qualification should be improved.

\section{Strengths and weakness}

As part of a Level 1 Trauma Center and a Center for EMS provision in southern Thailand, our database was large enough to provide insights on the epidemiological nature of injuries and the quality of EMS care in the southern part of Thailand. We were aware of data quality, a common problem in secondary data analysis. Thus, we carefully cleaned and verified the data to ensure reliability. Data on sensitive issues such as risky behaviors, mobile phone use, and alcohol and other drug use might be underestimated; however, we could report some significant adverse impacts. The findings from the descriptive statistics limited causal inferences being made. For example, we found that nonuse of EMS was associated with a high mortality rate.

\section{Conclusion}

The situation of both traffic and non-traffic preventable injuries is still critical in Thailand and urgently needs special attention. The study identified much room for improvement needed in the EMS services. Other prevention strategies in addition to service plans and legislation should be considered. Without improved interventions, the national goal will be difficult to reach, not only by 2020 , but sustained long-term.

\section{Conflicts of Interest}

None

\section{References}

1. World Health Organization. Health Statistics and Information System I Global Health Estimates [monograph on the Internet]. Geneva: WHO; 2014 [cited 2019 Sep 26]. Available from: http://www.who.int/healthinfo/global_burden_disease/en/

2. World Health Organization. Global Health Observatory Data Repository I By category I Road traffic deaths - Data by country [monograph on the Internet]. Geneva: WHO; 2019 [cited 2019 Nov 4]. Available from: http://apps.who.int/gho/data/node. main.A997 
3. Ditsuwan V, Veerman LJ, Barendregt JJ, Bertram M, Vos T. The national burden of road traffic injuries in Thailand. Popul Health Metr 2011;9:2.

4. Bureau of Non-communicable Diseases, Ministry of Public Health, Thailand. Annual Report 2018. Bangkok: Aksorn Graphic and Design; 2018.

5. Lotrakul M. Suicide in Thailand during the period 1998-2003. Psychiatry Clin Neurosci 2006;60:90-5.

6. World Health Organization. Global Health Observatory Data Repository | By category I Suicide rate estimates, agestandardized - Estimates by country [monograph on the Internet]. Geneva: WHO; 2018 [cited 2019 Sep 26]. Available from: http://apps.who.int/gho/data/node.main.MHSUICIDEASDR? lang=en

7. Hong J, Lee WK, Park H. Change in Causes of Injury-Related Deaths in South Korea, 1996-2006. J Epidemiol 2011;21:500-6.

8. Bulto LN, Dessie Y, Geda B. Magnitude, causes and characteristics of trauma victims visiting Emergency and Surgical Units of Dilchora Hospital, Eastern Ethiopia. Pan Afr Med J 2018;30: 177.

9. Santikarn C, Punyaratanabandhu P, Podhipak A, Rukronayut $K$, Sujirarat $D$, Wiengpitak $S$, et al. The establishment of injury surveillance in Thailand. Int J Inj Control Saf Promot 2019;6: 133-43.

10. National Institute for Emergency Medicine. Overview of Emergency Medical Operational Standards, Principles, Criteria and Protocols. Bangkok: The Ultimate Printing; 2014.

11. World Health Organization. The ICD-10 Classification of Injury, Poisoning and Certain Other Consequences of External
Causes: Clinical Descriptions and Diagnostic Guidelines. Geneva: WHO; 1992.

12. World Health Organization. The ICD-10 classification of external causes of morbidity and mortality: clinical descriptions and diagnostic guidelines. Geneva: WHO; 1992.

13. Gilboy N, Tanabe P, Travers DA, Rosenau AM, Eitel DR. Emergency Severity Index, Version 4: Implementation Handbook 2012 Edition. Rockville: Agency for Healthcare Research and Quality; 2011.

14. R. A Language and Environment for Statistical Computing [monograph on the Internet]. Vienna: R Foundation for Statistical Computing; 2016 [cited 2019 Sep 26]. Available from: https:// www.R-project.org/

15. World Health Organization. Road Safety Institutional and Legal Assessment Thailand. Bangkok: WHO; 2015.

16. Galbally R, Fidler A, Chowdhury M, Tang KC, Good S, Tantivess S. Ten-Year Review of Thai Health Promotion Foundation, Nov 2001-Nov 2011. Bangkok: Thai Health Promotion Foundation; 2012.

17. Wakabayashi M, Berecki-Gisolf J, Banwell C, Kelly M, Yiengprugsawan V, McKetin R, et al. Non-Fatal Injury in Thailand From 2005 to 2013: Incidence Trends and Links to Alcohol Consumption Patterns in the Thai Cohort Study. J Epidemiol 2016;26:471-80.

18. Health MoP. Service Plan for Emergency Care Service and Trauma. Bangkok: Ministry of Public Health; 2017.

19. Murad MK, Larsen S, Husum H. Prehospital trauma care reduces mortality. Ten-year results from a time-cohort and trauma audit study in Iraq. Scand J Trauma Resusc Emerg Med 2012; 20:13. 